\title{
Baseline Characteristics of the Fellow Eye in Patients with Neovascular Age-Related Macular Degeneration: Post Hoc Analysis of the VIEW Studies
}

\author{
Sebastian Wolf ${ }^{a}$ Francesco Bandello $^{b}$ Anat Loewenstein ${ }^{c}$ Jason Slakter ${ }^{d}$ \\ Todd Katz $^{\mathrm{e}}$ Olaf Sowade ${ }^{f}$ Jean-Francois Korobelnik ${ }^{g-i}$ \\ a Department of Ophthalmology, University Hospital Bern, Inselspital, University of Bern, Bern, Switzerland; \\ ${ }^{\text {b}}$ Department of Ophthalmology, University Vita-Salute Scientific Institute, San Raffaele, Milano, Italy; ${ }^{\mathrm{C}}$ Tel Aviv \\ Medical Center, Department of Ophthalmology, Tel Aviv, Israel; ' Vitreous-Retina-Macula Consultants of New York,

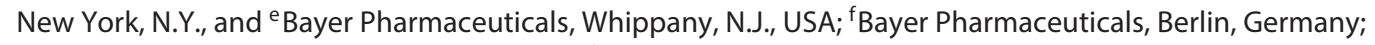 \\ ${ }^{9}$ Service d'ophtalmologie, CHU de Bordeaux, h University Bordeaux, ISPED, and 'Inserm, U1219, \\ Bordeaux Population Health Research Center, Bordeaux, France
}

\begin{abstract}
Key Words
Anti-VEGF agents · Best-corrected visual acuity · Bilateral disease - Choroidal neovascularization - Fellow eye .

Intravitreal aflibercept - Neovascular age-related macular degeneration $\cdot$ Pooled analysis · Ranibizumab
\end{abstract}

\begin{abstract}
Purpose: The aim was to describe baseline characteristics of the fellow eye of patients with neovascular age-related macular degeneration (nAMD). Methods: A pooled, post hoc analysis of patients with $\mathrm{nAMD}$ enrolled in the VIEW studies was carried out. The VIEW studies compared intravitreal aflibercept (monthly or every 2 months after 3 monthly injections) with monthly ranibizumab. Baseline choroidal neovascularization (CNV) status of fellow eyes and baseline bestcorrected visual acuity (BCVA) and lens status of all eyes were evaluated. Additional analyses evaluated the presence of drusen and pigment in fellow eyes. Results: When comparing both eyes, baseline BCVA was worse in $23.8 \%$ of fellow eyes and in $75.2 \%$ of study eyes. Lens status of fellow eyes
\end{abstract}

and study eyes was similar. Baseline visual acuity of the study eye and that of the fellow eye were not correlated. Most fellow eyes had signs of early AMD, with $34.6 \%(n=843)$ of fellow eyes having evidence of scarring. Conclusions: In patients in the VIEW studies, most fellow eyes had evidence of AMD, highlighting the importance of examining both eyes, with close follow-up thereafter, in order to detect and treat CNV earlier as needed.

(c) 2016 S. Karger AG, Basel

\section{Introduction}

Neovascular age-related macular degeneration (nAMD) is a leading cause of vision loss and blindness among individuals aged $>65$ years in industrialized countries $[1,2]$. Early therapies did not produce significant improvements in visual acuity (VA) [2]. The success of the first injectable anti-vascular endothelial growth factor (VEGF) agent, pegaptanib sodium, suggested that VEGF was driving the choroidal neovascularization $(\mathrm{CNV})$ as-

Jean-Francois Korobelnik 
Fig. 1. Distribution of baseline BCVA for fellow eye (upper panel) and study eye (lower panel). ETDRS = Early Treatment Diabetic Retinopathy Study.

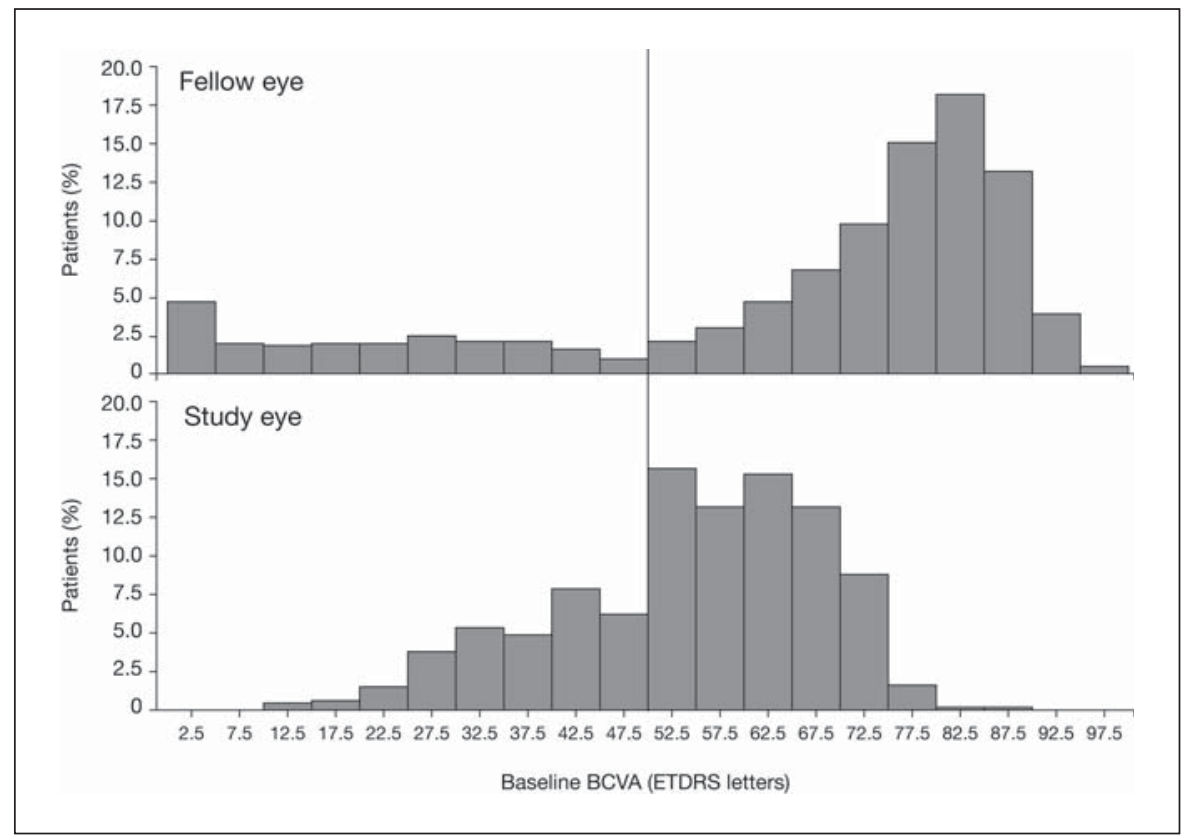

sociated with nAMD. Later, treatment with monthly ranibizumab was shown to prevent vision loss in most patients, and to meaningfully improve VA in about one third of patients [3, 4]; however, the potential risk of side effects plus the burden of monthly visits led to efforts to decrease injection and monitoring frequency [2].

Aflibercept, a recombinant fusion protein comprising key VEGF-binding domains of human VEGF receptors 1 and 2 fused to the Fc domain of human immunoglobulin G1, binds VEGF and placental growth factor, and demonstrated a higher binding affinity than ranibizumab or bevacizumab $[5,6]$ in preclinical studies, which could account for less frequent dosing. The VIEW studies compared intravitreal aflibercept injection, monthly or every 2 months after 3 initial monthly injections, with monthly ranibizumab. At week 52, all groups had similar visual, morphologic, and safety outcomes [2].

Previous reports have described the incidence of new $\mathrm{CNV}$ in the fellow eye during therapy. CNV in one eye of a patient with AMD is a strong risk factor for the development of CNV in the fellow eye (annual incidence: 4-19\%) [7-9]. Although nAMD trials have reported increased rates of CNV development in fellow eyes during therapy, perhaps due to more careful monitoring during clinical studies $[10,11]$, information on baseline incidence of $\mathrm{CNV}$ in fellow eyes was not reported. Since early detection of CNV in the fellow eye may lead to better long-term visual outcomes, it may be important to characterize fel- low eyes at baseline. The aim of this study was, therefore, to evaluate the baseline status of fellow eyes and to test the hypothesis that patients with worse VA in the fellow eye might present earlier, and with better VA in the study eye.

\section{Methods}

A pooled, post hoc analysis of patients enrolled in the VIEW studies was carried out in order to characterize the baseline status of fellow eyes, with a focus on baseline VA, lens status, and AMDassociated findings.

The VIEW studies (NCT00509795; NCT00637377) were randomized, double-masked, multicenter, parallel-group, active-controlled phase 3 trials that recruited $>2,400$ patients with treatmentnaïve nAMD from $>360$ centers worldwide. The trials compared standard of care (monthly ranibizumab) with 3 dosing regimens (0.5 mg monthly, $2 \mathrm{mg}$ monthly, $2 \mathrm{mg}$ every other month following 3 initial monthly injections) of intravitreal aflibercept injection [2]. The VIEW study protocols were approved by the institutional review boards or ethics committees for each clinical site and all participants provided written informed consent.

In the original VIEW studies, for patients who met eligibility criteria in both eyes, the eye with the worse VA was selected as the study eye. In this post hoc analysis, 3 different sources within the VIEW database were compared. The Past Medical History and Adverse Event (PMH) data were used to search for previous diagnoses of CNV before baseline. The Prior and Concomitant medications data (CONMED) used CONMED codes for 'first use of ranibizumab (Lucentis ${ }^{\circledR}$ )/bevacizumab $\left(\right.$ Avastin $^{\circledR}$ )/pegaptanib (Macugen ${ }^{\circledR}$ ) in fellow eye before baseline' to search for first use of CNV medication. The Digital Angiography Reading Center (DARC) database 
used 'Choroidal Neovascularization; Fellow Eye' to search for anatomic evidence of fellow eye $\mathrm{CNV}$ at baseline. Inclusion required the identification in $\geq 1$ database. Baseline best-corrected VA (BCVA) and lens status were assessed for all eyes. Baseline evidence of current/prior CNV, presence of hard/soft drusen, presence of intermediate/large drusen, and presence/location of pigment were assessed for fellow eyes only. Geographic atrophy could not be evaluated.

\section{Results}

\section{Patients}

Baseline characteristics of fellow eyes versus study eyes were described for 2,412 patients from the VIEW studies.

\section{Baseline BCVA: Study Eye versus Fellow Eye}

The mean (standard deviation) BCVA was 65.2 (25.8) letters $(\sim 20 / 50)$ in fellow eyes versus 53.8 (13.6) letters $(\sim 20 / 80)$ in study eyes. Severe visual impairment $[\leq 36$ letters $(\sim 20 / 200)$ ] was seen in $16.9 \%$ of fellow eyes versus $12.4 \%$ of study eyes. Note that in the VIEW studies, only eyes with a letter score of 25-75 letters could be selected as study eyes. BCVA $>80$ letters $(\sim 20 / 25)$ was seen in $33.2 \%$ of fellow eyes versus $0.2 \%$ of study eyes. Baseline BCVA was worse in fellow eyes in $23.8 \%$ of patients and in study eyes in $75.2 \%$ of patients $(0.3 \%$ missing; $0.6 \%$ baseline VA equal in both eyes). Distribution of baseline $\mathrm{BCVA}$ is shown in figure 1 .

\section{Baseline Characteristics: Fellow Eye}

Overall, 2.5\% of fellow eyes had anti-VEGF use prior to the first study day. Most fellow eyes had signs of AMD at baseline. Baseline drusen and pigment characteristics were assessed; only $10.0 \%(n=226)$ of fellow eyes did not have drusen and only $11.8 \%(n=132 / 1,120$; pigment information only available for VIEW 1) did not have pigment at baseline (table 1). Breakdown of VA in fellow eyes with/without $\mathrm{CNV}$ is shown in figure 2. At baseline, $843 / 2,412$ patients $(34.6 \%)$ presented with scarring (presence of fibrosis) as a sign of prior CNV. Of these 843, most $(64.8 \% ; \mathrm{n}=546)$ were categorized in $>1$ database as having CNV. Some patients were categorized as having CNV in only 1 database $(16.1 \% ; n=136$ categorized in DARC only, $19.0 \% ; \mathrm{n}=161$ categorized in $\mathrm{PMH}$ only). The lens status of fellow eyes was similar to that of study eyes; pseudophakia was seen in $34.3 \%$ (fellow eyes) and $38.0 \%$ (study eyes).

Baseline Study Eye VA versus Baseline Fellow Eye VA

We examined whether patients with worse fellow eye VA present earlier and with better VA in the study eye.

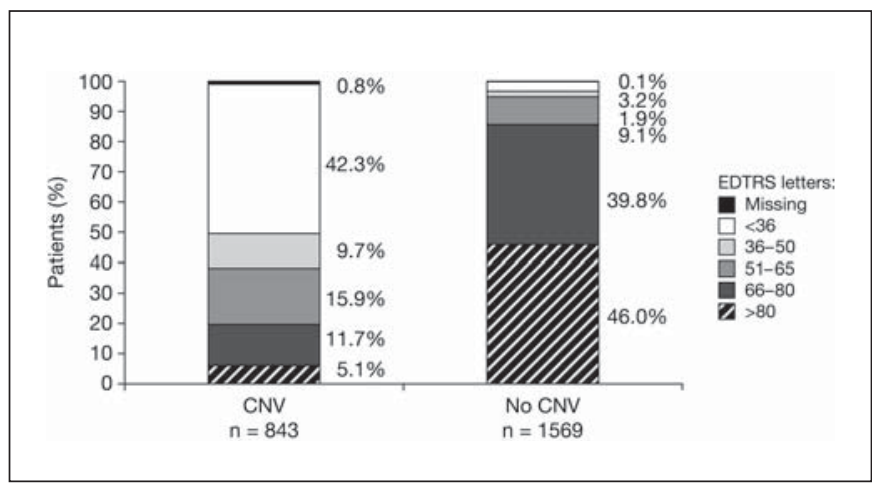

Fig. 2. Baseline BCVA and CNV in the fellow eye. ETDRS = Early Treatment Diabetic Retinopathy Study.

Table 1. Baseline drusen and pigment characteristics in fellow eyes

$\begin{array}{lc}\text { Drusen }^{\mathrm{a}} & \\ \text { Hard } & 2,011(88.6) \\ \text { Soft } & 1,693(74.5) \\ \text { None } & 226(10.0) \\ \text { Number of intermediate/large drusen } & \mathrm{b}(\mathrm{n}=2,256) \\ \text { Not entered } & 102(4.5) \\ 0-5 & 1,124(49.8) \\ 6-10 & 255(11.3) \\ 11-20 & 259(11.5) \\ >20 & 522(23.1) \\ \text { Pigment }^{\mathrm{c}}(\mathrm{n}=1,120) & \\ \text { Extrafoveal } & 985(87.9) \\ \text { Subfoveal } & 223(19.9) \\ \text { None } & 132(11.8)\end{array}$

Figures are numbers with percentages in parentheses. Characteristics are not mutually exclusive. ${ }^{a}$ Hard drusen have well-defined/distinct borders (usually small/intermediate); soft drusen have confluent/indistinct borders (usually intermediate/ large). ${ }^{\mathrm{b}}$ Intermediate $\geq 63$ to $<125 \mu \mathrm{m}$; large $\geq 125 \mu \mathrm{m}$. ${ }^{\mathrm{c}}$ Information only available for VIEW 1 patients $(n=1,120)$.

The mean (SD) study eye VA was 53.7 (13.8) when the baseline fellow eye VA was $\geq 50$ letters, and 54.0 (12.7) when the baseline fellow eye VA was $<50$ letters, confirming that our hypothesis was not supported.

\section{Discussion}

AMD is a bilateral disease, and risk of neovascularization in a fellow eye increases over time after initial diagnosis [12]. Hence, it is important to determine the status of both eyes at diagnosis. The current analysis showed 
that most fellow eyes in the VIEW studies had signs of AMD at baseline, confirmed by the presence of drusen and pigment. Approximately one third of the fellow eyes also had evidence of $\mathrm{CNV}$ at baseline.

The average baseline condition of fellow eyes at the time these trials commenced may have been worse than the average baseline condition of fellow eyes today. Management of nAMD is constantly evolving with availability of new therapies and diagnostic tools, as well as ongoing evaluation of optimal dosing regimens. Historically, nAMD was treated with laser photocoagulation, which often caused a permanent loss of central vision. Earlier treatments that followed generally decreased severe vision loss with less damage to associated choroid and retina [13]. In the current study, $~ 35 \%$ of patients showed evidence of scarring. It was not until the early 2000s that VEGF inhibitors became available as treatment options for nAMD that stabilize or significantly improve VA. Questions remain about best dosing regimens, and efforts to minimize the burden of frequent injections sometimes result in undertreatment. As advanced therapies continue to be introduced and care of patients with nAMD progresses, it is expected that the prognosis for these patients will improve, resulting in better outcomes.

It can be speculated that if one eye already has suffered visual loss due to CNV, the second eye would be followed closely and changes would be noticeable early. Early diagnosis should lead to presenting vision in the second eye being better than that in the initial eye. However, this was not supported by the current analysis, which found no difference in baseline VA of study eyes as a function of baseline VA of fellow eyes.

This analysis was potentially limited by the fact that specific inclusion and exclusion criteria are imposed on patients enrolled in clinical trials, and this may introduce a selection bias. For example, for those patients who met eligibility criteria in both eyes, the eye with the worse VA was selected as the study eye. However, the better-seeing eye was selected as the study eye in $575 / 2,412(23.8 \%)$ patients in VIEW 1 and 2; in these patients, the baseline BCVA score in the fellow eye was $<25$ letters in 294/575 (51.1\%) patients; in the remaining $281 / 575$ (48.9\%) patients, other reasons were present not to select the worse eye as the study eye. Nevertheless, these patient populations may not truly reflect those seen in real-world clinical practice; this, and the resultant characterization of the patients in this analysis, should be taken into consideration when interpreting these results.

\section{Conclusions}

The risk of development of CNV in untreated eyes after diagnosis of the initial eyes has been well described; however, information on the prevalence of $\mathrm{CNV}$ in the second eye at the time of the initial diagnosis is scarce. In this first report describing baseline characteristics of fellow eyes using data from the VIEW study, most patients had evidence of AMD characteristics in fellow eyes at baseline, with one third presenting with signs of CNV. As AMD is a bilateral disease, it is important to evaluate the status of both eyes during clinical examination even if only 1 eye presents with CNV in order to be able to detect and treat early for optimal outcomes. Close follow-up is needed, as fellow eyes are at high risk of developing $\mathrm{CNV}$ in the near future.

\section{Acknowledgements}

The authors take full responsibility for the scope, direction, and content of the manuscript; all authors have read and approved the final submitted manuscript. Additional contributions to the manuscript were made by Richard Morton, MSc. Medical writing support was provided by Michelle Olsher, $\mathrm{PhD}$, and Leigh Prevost, BSc Pharm Hons, of PAREXEL, which was funded by Bayer Pharmaceuticals.

\section{Disclosure Statement}

Sebastian Wolf: consultant to and/or advisory board member for Alcon, Allergan, Bayer Pharmaceuticals, Heidelberg Engineering, Novartis, Roche, Zeiss; Francesco Bandello: advisory board member for Allergan, Novartis, Théa, Bayer-Schering, Pfizer, Alcon, Bausch and Lomb, Genentech, Alimera Sciences, Sanofi-Aventis, Thrombogenics, and Hoffmann-La Roche, and data safety monitoring board member for Novagali Pharma; Anat Loewenstein: consultant to Allergan, Alimera, Bayer Pharmaceuticals, LaRoche, Novartis, Notal Vision, and Teva, advisory board member for Novartis; Jason Slakter: grant research support for Digital Angiography Reading Center, Bayer Pharmaceuticals, Genentech, Genzyme, GSK, Lpath, Ohr, Oraya, Regeneron, SanofiAventis, Santen, Thrombogenics, and Tyrogenex, consultant to Genentech, Ohr, Oraya, and Regeneron, stock ownership: SKS Ocular and Ohr Pharmaceutical; Todd Katz: employee of Bayer Pharmaceuticals; Olaf Sowade: employee of Bayer Pharmaceuticals; Jean-Francois Korobelnik: consultant for Alcon, Alimera, Allergan, Bayer Pharmaceuticals, Horus, Novartis, Roche, Thea, and Zeiss.
Wolf/Bandello/Loewenstein/Slakter/Katz/ Sowade/Korobelnik 


\section{References}

1 Congdon NG, Friedman DS, Lietman T: Important causes of visual impairment in the world today. JAMA 2003;290:2057-2060.

2 Heier JS, Brown DM, Chong V, Korobelnik JF, Kaiser PK, Nguyen QD, Kirchhof B, Ho A, Ogura Y, Yancopoulos GD, Stahl N, Vitti R, Berliner AJ, Soo Y, Anderesi M, Groetzbach G, Sommerauer B, Sandbrink R, Simader C, Schmidt-Erfurth U: Intravitreal aflibercept (VEGF trap-eye) in wet age-related macular degeneration. Ophthalmology 2012;119: 2537-2548.

3 Brown DM, Kaiser PK, Michels M, Soubrane G, Heier JS, Kim RY, Sy JP, Schneider S: Ranibizumab versus verteporfin for neovascular age-related macular degeneration. N Engl J Med 2006;355:1432-1444.

4 Rosenfeld PJ, Brown DM, Heier JS, Boyer DS, Kaiser PK, Chung CY, Kim RY: Ranibizumab for neovascular age-related macular degeneration. N Engl J Med 2006;355:1419-1431.

5 Holash J, Davis S, Papadopoulos N, Croll SD, Ho L, Russell M, Boland P, Leidich R, Hylton D, Burova E, Ioffe E, Huang T, Radziejewski C, Bailey K, Fandl JP, Daly T, Wiegand SJ, Yancopoulos GD, Rudge JS: VEGF-Trap: a VEGF blocker with potent antitumor effects. Proc Natl Acad Sci USA 2002;99:11393-11398.

6 Papadopoulos N, Martin J, Ruan Q, Rafique A, Rosconi MP, Shi E, Pyles EA, Yancopoulos GD, Stahl N, Wiegand SJ: Binding and neutralization of vascular endothelial growth factor (VEGF) and related ligands by VEGF Trap, ranibizumab and bevacizumab. Angiogenesis 2012;15:171-185.

7 Macular Photocoagulation Study Group: Risk factors for choroidal neovascularization in the second eye of patients with juxtafoveal or subfoveal choroidal neovascularization secondary to age-related macular degeneration. Arch Ophthalmol 1997;115:741-747.

8 Solomon SD, Jefferys JL, Hawkins BS, Bressler NM: Incident choroidal neovascularization in fellow eyes of patients with unilateral subfoveal choroidal neovascularization secondary to age-related macular degeneration: SST report No 20 from the Submacular Surgery Trials Research Group. Arch Ophthalmol 2007; 125:1323-1330.

9 Wang JJ, Rochtchina E, Lee AJ, Chia EM, Smith W, Cumming RG, Mitchell P: Ten-year incidence and progression of age-related maculopathy: the blue Mountains Eye Study. Ophthalmology 2007;114:92-98.

10 Barbazetto IA, Saroj N, Shapiro H, Wong P, Ho AC, Freund KB: Incidence of new choroidal neovascularization in fellow eyes of patients treated in the MARINA and ANCHOR trials. Am J Ophthalmol 2010;149:939-946.

11 Maguire MG, Daniel E, Shah AR, Grunwald JE, Hagstrom SA, Avery RL, Huang J, Martin RW, Roth DB, Castellarin AA, Bakri SJ, Fine SL, Martin DF: Incidence of choroidal neovascularization in the fellow eye in the comparison of age-related macular degeneration treatments trials. Ophthalmology 2013;120: 2035-2041.

12 Amissah-Arthur KN, Panneerselvam S, Narendran N, Yang YC: Optical coherence tomography changes before the development of choroidal neovascularization in second eyes of patients with bilateral wet macular degeneration. Eye (Lond) 2012;26:394-399.

13 Brown DM, Regillo CD: Anti-VEGF agents in the treatment of neovascular age-related macular degeneration: applying clinical trial results to the treatment of everyday patients. Am J Ophthalmol 2007;144:627-637. 